\title{
High-Performance Flexible Asymmetric Supercapacitor Based on CoAl-LDH and rGO Electrodes
}

\author{
Shuoshuo $\mathrm{Li}^{1,2} \cdot$ Pengpeng Cheng ${ }^{1,2} \cdot$ Jiaxian Luo $^{1,2} \cdot$ Dan $\mathrm{Zhou}^{1,2} \cdot$ Weiming $\mathrm{Xu}^{1,2} \cdot J_{i n g w e i} \mathrm{Li}^{1,2} \cdot$ \\ Ruchun $\mathrm{Li}^{1,2}$ - Dingsheng Yuan ${ }^{1,2}$
}

Received: 23 December 2016/ Accepted: 15 January 2017/Published online: 18 February 2017

(C) The Author(s) 2017. This article is published with open access at Springerlink.com

\section{Highlights}

- CoAl-LDH (layer double hydroxide) electrode and binder-free rGO (reduced graphene oxide) electrode were successfully synthesized and assembled to produce a flexible ASC (asymmetric supercapacitor).

- The assembled ASC device exhibited excellent capacitive performance.

\begin{abstract}
A flexible asymmetric supercapacitor (ASC) based on a CoAl-layered double hydroxide (CoAl-LDH) electrode and a reduced graphene oxide (rGO) electrode was successfully fabricated. The CoAl-LDH electrode as a positive electrode was synthesized by directly growing CoAl-LDH nanosheet arrays on a carbon cloth (CC) through a facile hydrothermal method, and it delivered a specific capacitance of $616.9 \mathrm{~F} \mathrm{~g}^{-1}$ at a current density of $1 \mathrm{~A} \mathrm{~g}^{-1}$. The rGO electrode as a negative electrode was synthesized by coating rGO on the CC via a simple dipcoating method and revealed a specific capacitance of $110.0 \mathrm{~F} \mathrm{~g}^{-1}$ at a current density of $2 \mathrm{~A} \mathrm{~g}^{-1}$. Ultimately, the advanced ASC offered a broad voltage window $(1.7 \mathrm{~V})$ and exhibited a high superficial capacitance of $1.77 \mathrm{~F} \mathrm{~cm}^{-2}$ at $2 \mathrm{~mA} \mathrm{~cm}{ }^{-2}$ and a high energy density of $0.71 \mathrm{mWh} \mathrm{cm}^{-2}$ at a power density of $17.05 \mathrm{~mW} \mathrm{~cm}^{-2}$, along with an excellent cycle stability (92.9\% capacitance retention over 8000 charge-discharge cycles).
\end{abstract}

Dingsheng Yuan

tydsh@jnu.edu.cn

1 School of Chemistry and Materials Science, Jinan University, Guangzhou 510632, People's Republic of China

2 Guangzhou Key Laboratory of Vacuum Coating Technologies and New Energy Materials, Jinan University, Guangzhou 510632, People's Republic of China

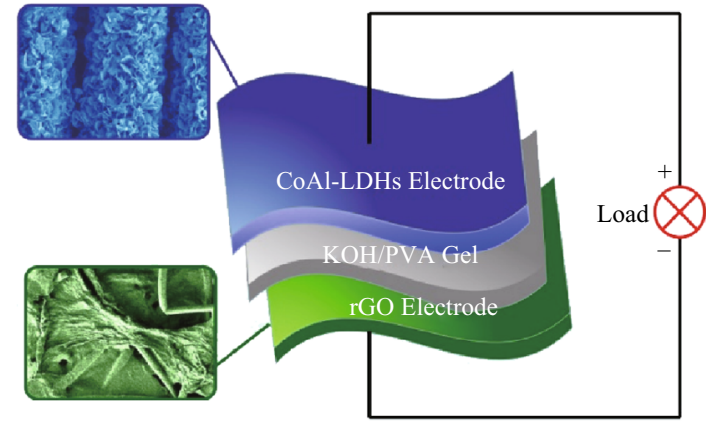

Keywords Flexible asymmetric supercapacitor · Layer double hydroxides - Reduced graphene oxide - Cycle stability

\section{Introduction}

The increasing demand for portable electronic devices and hybrid vehicles has stimulated the development of highperformance flexible energy storage devices [1-5]. Flexible supercapacitors (SCs), which have played a key role in medical treatment, military, entertainment, and industry, are considered as potential candidates for flexible and 
portable energy storage devices because of their high flexibility and light weight [6-9]. Although SCs have desired properties such as fast charge-discharge rate, high power density, and cycling stability, the energy density of flexible SCs needs to be improved to meet the fast-growing market for portable electronic devices and the development of hybrid vehicles [10-15].

According to the equation of energy density ( $E=0.5$ $\mathrm{CV}^{2}$ ), the energy density can be enhanced by increasing the specific capacitance $(C)$ or the voltage window (V) [16-19]. On the one hand, developing appropriate electrode materials favors enhancing the specific capacitance and correspondingly improving the energy density [20-22]. Based on the energy storage mechanisms, electrode materials can be classified into two types: electric double-layer capacitors (EDLC) and pseudocapacitors. The EDLC electrode material stores energy based on electrostatic charge accumulation on the surface between the electrode and electrolyte [23-26]. Carbon materials have mostly been used because of their high specific surface area, good electrical conductivity, and excellent stability. Among them, graphene, a single-atom-thick sheet of hexagonally arrayed $s p^{2}$-bonded carbon atoms, which has a high theoretical specific capacitance of $550 \mathrm{~F} \mathrm{~g}^{-1}$, has emerged as a promising candidate for electrode materials [27-30]. Pseudocapacitive electrode materials mainly rely on fast and reversible faradic reactions to store energy. Transition metal oxides and hydroxides have extensively been developed as electrode materials of this type. However, considering their poor electronic conductivity, various transition metal hydroxides and oxides combined with electrically conductive frameworks, such as a carbon cloth (CC) and $\mathrm{Ni}$ foam, have attracted increasing attention [31-33]. For example, Yu et al. have reported that $\mathrm{NiFe}_{2} \mathrm{O}_{4}$ nanoparticles can be directly grown on a flexible $\mathrm{CC}$ substrate by a facile surfactant-assisted hydrothermal method that showed good electrochemical properties [34]. This designed device possessed several advantages including flexibility, a binder-free process, and portability, which are more desirable for portable electronic devices.

On the other hand, constructing an asymmetric system with different positive and negative electrode materials can increase the voltage window and thus enhance the energy density. Fang et al. successfully fabricated a flexible coaxial-type fiber solid-state asymmetrical SC (ASC) based on $\mathrm{Ni}_{3} \mathrm{~S}_{2}$ nanorod array electrodes and pen-ink electrode. Compared to symmetric SCs (SSCs) based on $\mathrm{Ni}_{3} \mathrm{~S}_{2}$ electrodes, the ASC device provides an increased energy density [35]. Based on the above consideration, here, a flexible ASC device was designed, including CoAl-layered double hydroxide (CoAl-LDH) and reduced graphene oxide (rGO) grown on the $\mathrm{CC}$ as the positive electrode and the negative electrode, respectively. Accordingly, the CoAl-LDH electrode with ultrathin nanosheets and porous nanostructure showed a high specific capacitance of $616.9 \mathrm{~F} \mathrm{~g}^{-1}$ at a current density of $1 \mathrm{~A} \mathrm{~g}^{-1}$. As the negative electrode, $\mathrm{rGO}$ showed a specific capacitance of $110 \mathrm{~F} \mathrm{~g}^{-1}$ at a current density of $2 \mathrm{~A} \mathrm{~g}^{-1}$. When assembled together, the flexible ASC delivered a high capacitance of $1.77 \mathrm{~F} \mathrm{~cm}^{-2}$ at $2 \mathrm{~mA} \mathrm{~cm}^{-2}$ and a high energy density of $0.71 \mathrm{mWh} \mathrm{cm}^{-2}$ at a power density of $17.05 \mathrm{~mW} \mathrm{~cm} \mathrm{~cm}^{-2}$.

\section{Experimental Section}

\subsection{Preparation of CoAl-LDH Nanosheet on CC (CC@CoAl-LDHs)}

The CC $\left(1.0 \times 2.0 \mathrm{~cm}^{2}\right)$ was cleaned with concentrated hydrochloric acid, acetone, and deionized water and then dried. The cleaned $\mathrm{CC}$ was immersed in $2.0 \mathrm{~mol} \mathrm{~L}^{-1}$ $\mathrm{Co}\left(\mathrm{NO}_{3}\right)_{2} \cdot 6 \mathrm{H}_{2} \mathrm{O}$ solution for $1 \mathrm{~min}$ and then removed. The resulting CC was dried at $60{ }^{\circ} \mathrm{C}$ for $15 \mathrm{~min}$. The whole procedure was repeated three times. The preprocessed CC was placed into a Teflon-lined autoclave with $2.0 \mathrm{mmol}$ $\mathrm{Co}\left(\mathrm{NO}_{3}\right)_{2} \cdot 6 \mathrm{H}_{2} \mathrm{O}, 2.0 \mathrm{mmol} \mathrm{Al}\left(\mathrm{NO}_{3}\right)_{3}, 4.0 \mathrm{mmol} \mathrm{CO}\left(\mathrm{NH}_{2}\right)_{2}$, $8.0 \mathrm{mmol} \mathrm{NH}_{4} \mathrm{~F}$, and $60.0 \mathrm{~mL} \mathrm{H}_{2} \mathrm{O}$. Then, the autoclave was sealed and heated in an oven at $140{ }^{\circ} \mathrm{C}$ for $16 \mathrm{~h}$. After cooling down to $25^{\circ} \mathrm{C}$, the $\mathrm{CC}$ was washed with deionized water and alcohol several times and dried at $60{ }^{\circ} \mathrm{C}$ for $24 \mathrm{~h}$.

\subsection{Preparation of rGO on CC (CC@ rGO)}

GO was prepared using Hummer's method. Aqueous GO solution $\left(50.0 \mathrm{~mL}, 1.0 \mathrm{mg} \mathrm{mL}^{-1}\right)$ was reacted in a Teflonlined autoclave at $180^{\circ} \mathrm{C}$ for $6 \mathrm{~h}$. After cooling down to room temperature, the products were filtered, washed, and freeze-dried. Then, $10.0 \mathrm{mg}$ rGO powders were dispersed in $10.0 \mathrm{~mL} \mathrm{~N}$-methyl-2-pyrrolidone (NMP) and ultrasonicated for $1 \mathrm{~h}$ to form stable aqueous rGO. The $\mathrm{CC}$ was immersed in aqueous rGO for $2 \mathrm{~min}$, removed, and dried at $60{ }^{\circ} \mathrm{C}$ for $5 \mathrm{~min}$. The process was repeated 10 times to obtain CC@rGO.

\subsection{Materials Characterization}

The samples were characterized using a MSAL-XD2 X-ray diffractometer (XRD, Cu Ka, $40 \mathrm{kV}, 20 \mathrm{~mA}, \lambda=1.5406 \AA$ ). The morphologies were examined by scanning electron microscopy (SEM, ZEISS Ultra 55) and field-emission transmission electron microscopy (FETEM, JEM2010) operating at $200 \mathrm{kV}$. Nitrogen sorption isotherms of the asprepared materials were studied using a Micromeritics TriStar 3000 analyzer at $77 \mathrm{~K}$. The plot of specific surface area was deduced from the isotherm analysis of the adsorption data at a relative pressure $\left(\mathrm{P} / \mathrm{P}_{0}\right)$ of $0-1.0$, and the average pore 
diameters were collected from the peak value of the pore diameter distribution.

\subsection{Electrochemical Measurements}

All electrochemical measurements were taken on an electrochemical workstation (CHI 660D, CH Instruments, Inc.) at room temperature in a conventional three-electrode system. A Ni foil and a $\mathrm{Hg} / \mathrm{HgO}$ electrode were used as the counter and reference electrodes, respectively. The working electrode was measured by cyclic voltammetry (CV) and galvanostatic charge-discharge in a 6-M KOH aqueous solution.

\subsection{Flexible Asymmetric Supercapacitor Devices}

The flexible asymmetric SC consists of CC@CoAl-LDHs as the positive electrode, $\mathrm{CC} @ \mathrm{rGO}$ as the negative electrode, and PVA/KOH as the electrolyte and separator. The assembly process is as follows: PVA/KOH gel was prepared by mixing $6 \mathrm{~g}$ of PVA powder into $100 \mathrm{~mL}$ of $6 \mathrm{M}$ $\mathrm{KOH}$ aqueous solution. The mixture was heated to $90{ }^{\circ} \mathrm{C}$ with stirring until it became clear. Then, the positive and negative electrodes were immersed into the PVA/KOH gel for $15 \mathrm{~min}$ and then solidified for $10 \mathrm{~min}$. Next, the electrodes were immersed in the gelled electrolyte again and assembled into a sandwich structure. The fabrication of a flexible ASC cell was completed after the gel electrolyte solidified at room temperature.

\section{Results and Discussion}

\subsection{Positive Electrode}

Figure 1a shows the XRD pattern of CoAl-LDHs. A strong peak appeared at $2 \theta=12.2^{\circ}$ and $23.9^{\circ}$, corresponding to the diffraction lattice of the (003) and (006) planes, respectively, which suggested that the as-prepared material had a hydrotalcite-type structure [17]. Fourier transform infrared spectroscopy (FTIR) of the as-prepared CoAlLDHs is shown in Fig. 1b. The strong absorption peak at $3446 \mathrm{~cm}^{-1}$ corresponded to the $\mathrm{O}-\mathrm{H}$ stretching vibration of the hydroxyl groups. Peaks at 1370 and $789 \mathrm{~cm}^{-1}$ corresponded to the $v 3$ vibration and bending modes of $\mathrm{CO}_{3}{ }^{2-}$, respectively. In addition, the weak absorption at $1636 \mathrm{~cm}^{-1}$ was attributed to the bending vibration of water molecules. Other peaks below $800 \mathrm{~cm}^{-1}$ were related to the metal-oxygen $(\mathrm{M}-\mathrm{O})$ stretching and bending vibrations [36].

$\mathrm{N}_{2}$ adsorption and desorption isotherms were performed to analyze the porous structure and porous size distribution of the CoAl-LDH nanosheets, as shown in Fig. 1c. The sample presented a type III curve with a H1 hysteresis loop at a high relative pressure, demonstrating the presence of macropores and mesopores. The specific surface area of CoAl-LDHs can be calculated using the Brunauer-Emmett-Teller (BET) equation and could reach up to $45 \mathrm{~m}^{2} \mathrm{~g}^{-1}$. The Barrett-Joyner-Halenda (BJH) pore-sizedistribution curve is shown in Fig. 1c (insets). A noticeable narrower peak of the pore size distribution could be observed and showed the desired pore size distribution at $4 \mathrm{~nm}$. The abundant pores could potentially enhance electrolyte diffusion and improve the power capability of the obtained sample. Furthermore, the energy-dispersive X-ray spectroscopy (EDX) spectrum (Fig. 1d) revealed that the CoAl-LDH nanosheets mainly contained $\mathrm{Co}, \mathrm{Al}, \mathrm{Cu}, \mathrm{O}$, and $\mathrm{C}$, while most of the $\mathrm{C}$ and $\mathrm{Cu}$ signals were from the carbon-supported and $\mathrm{Cu}$ grid. All these results indicate that CoAl-LDHs were successfully prepared.

The morphologies of CC@CoAl-LDHs were characterized by SEM and TEM. Figure 2a shows the SEM image of CC@CoAl-LDHs. It is clearly observed that CoAlLDHs uniformly covered the $\mathrm{CC}$ with a dense packing. The magnified SEM image in Fig. 2b revealed that the CoAlLDHs are composed of around 10-nm-thick nanosheets, which could increase the specific surface area of CoAlLDHs and yield excellent electrochemical properties. In addition, the TEM images of CoAl-LDHs scraped from the $\mathrm{CC}$ are displayed in Fig. 2c, d. Figure 2c shows the CoAlLDH nanosheets corresponding to the SEM. The HRTEM image of the CoAl-LDH nanosheet (Fig. 2d) showed a lattice spacing of $0.8 \mathrm{~nm}$, corresponding to the (003) plane.

To investigate the electrochemical performance of the CC@CoAl-LDHs, the CV curves were measured at different scan rates in $6 \mathrm{M} \mathrm{KOH}$ solution, as shown in Fig. 3a. A pair of redox peaks was present in every $\mathrm{CV}$ curve, which indicated that the CoAl-LDHs were typical pseudocapacitor materials. All the redox peaks were symmetrical at different scan rates, implying the excellent reversible redox reaction at/near the surface of the CoAlLDH electrode. The galvanostatic charge-discharge curve of CoAl-LDHs at different current densities is shown in Fig. 3b. The presence of an obvious charge-discharge platform further evidenced that CoAl-LDHs possessed pseudocapacitance characteristics. Meanwhile, the specific capacitance of CoAl-LDHs in Fig. 3c could be calculated from the discharge time using the following equation:

$C=\frac{i t}{m \Delta V}$

where $i, t, m$, and $\Delta V$ represent the discharge current $(A)$, discharge time $(s)$, mass of active materials $(g)$, and total potential deviation $(V)$, respectively. The CoAl-LDHs delivered a high specific capacitance of $616.9 \mathrm{~F} \mathrm{~g}^{-1}$ at a current density of $1 \mathrm{~A} \mathrm{~g}^{-1}$. Simultaneously, a capacitance 
(a)

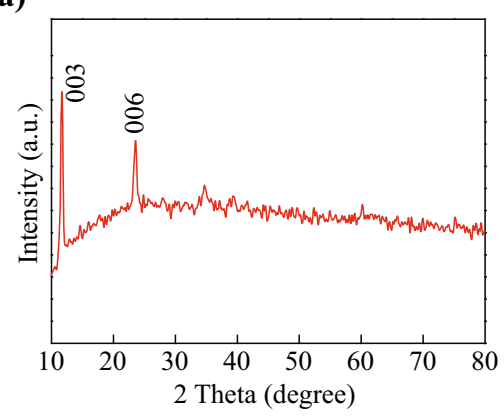

(c)

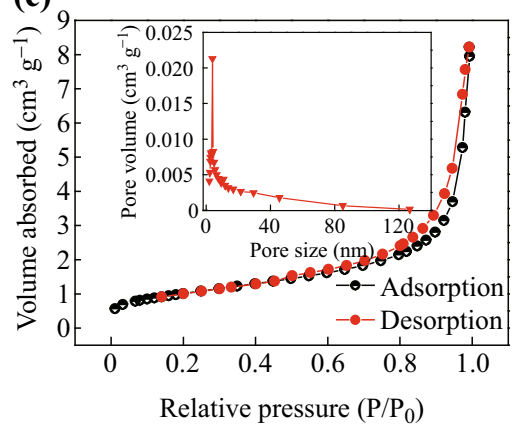

(b)

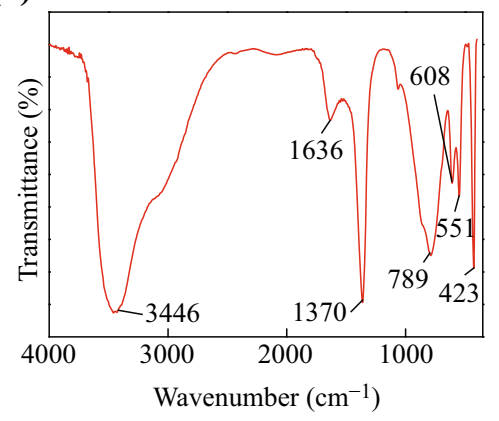

(d)

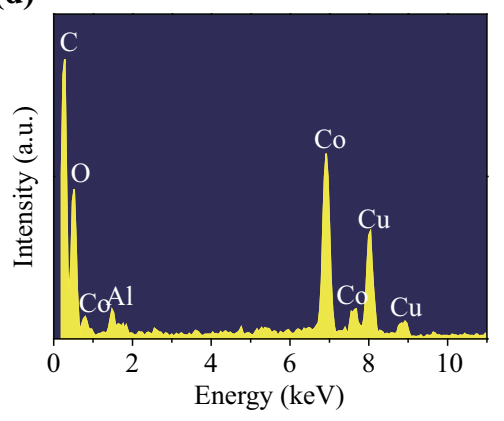

Fig. 1 a XRD pattern; b FTIR; $\mathbf{c} \mathrm{N}_{2}$ adsorption-desorption isotherms and pore sizes distribution (inset); $\mathbf{d}$ EDX spectroscopy of CoAl-LDHs
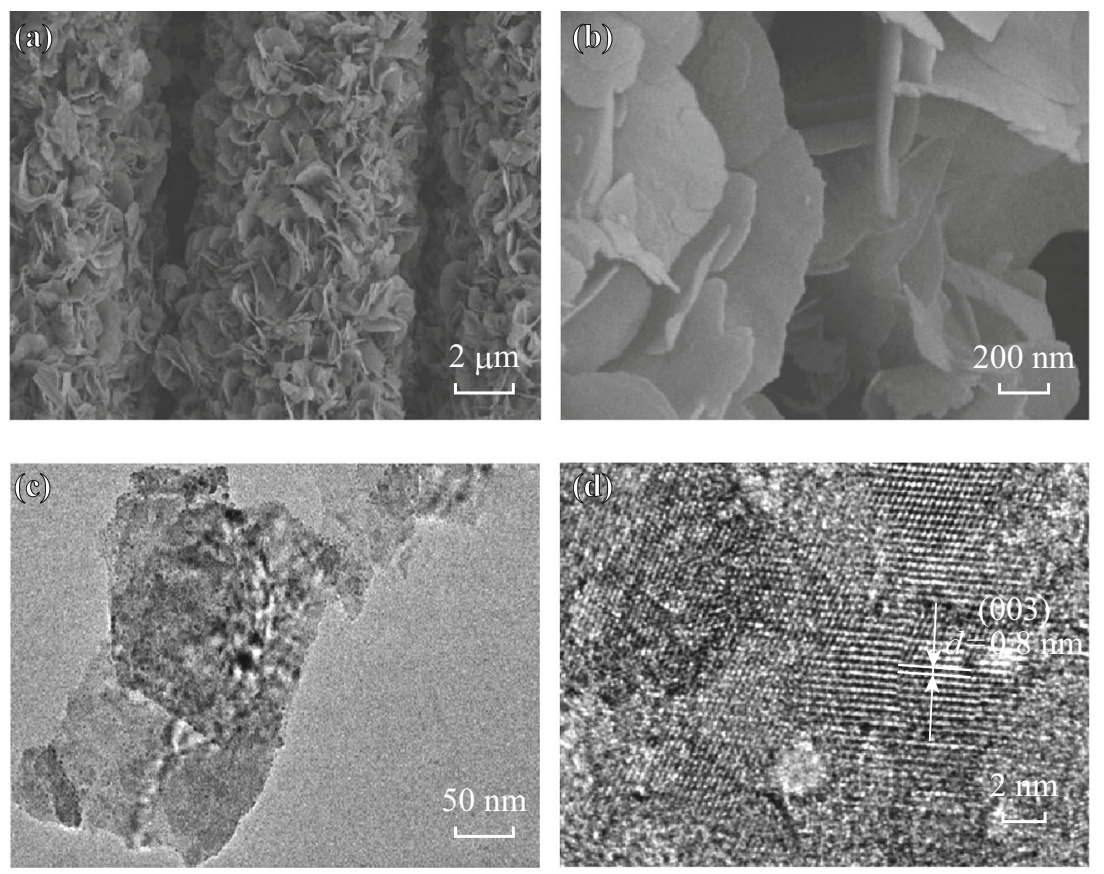

Fig. 2 a, b SEM images of CoAl-LDHs on CC electrode and $\mathbf{c}, \mathbf{d}$ TEM images of CoAl-LDHs

of $454.4 \mathrm{~F} \mathrm{~g}^{-1}$ was still retained at a very high current density of $20 \mathrm{~A} \mathrm{~g}^{-1}$, indicating a good rate capability. These excellent electrochemical properties could be attributed to three factors: (1) The CoAl-LDHs uniformly covered on the surface of the CC could improve the electron transport from the active materials to the current collector; (2) the two-dimensional porous structure could accelerate the permeation of electrolyte for fast and reversible faradic reactions, increase the specific surface area of CoAl-LDHs and accordingly enhance the electrochemical properties; (3) the redox reaction between $\mathrm{Co}^{2+}$ and $\mathrm{Co}^{3+}$ in CoAl-LDHs could contribute more efficiently 
(a)

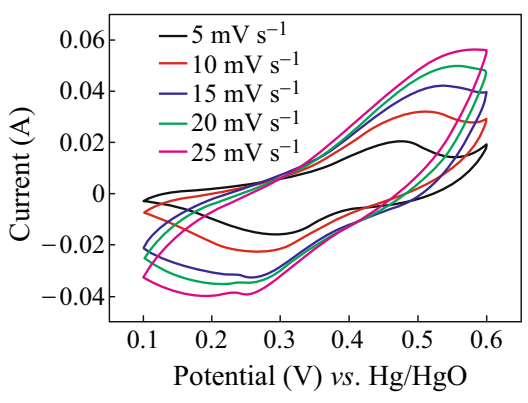

(c)

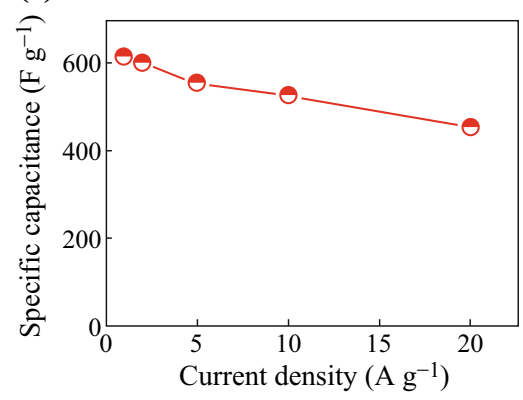

(b)

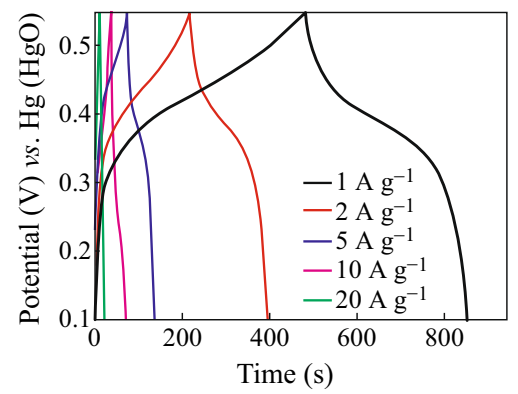

(d)

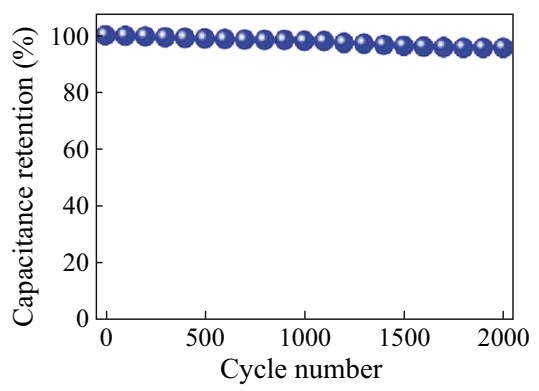

Fig. 3 Electrochemical performances of the CoAl-LDHs@CC electrode: a CVs at different scan rates; b GCD curves at different current densities; c Plot of C sp versus current density; d Cycling performances during 2000 cycles at a large current density of $10 \mathrm{~A} \mathrm{~g}^{-1}$
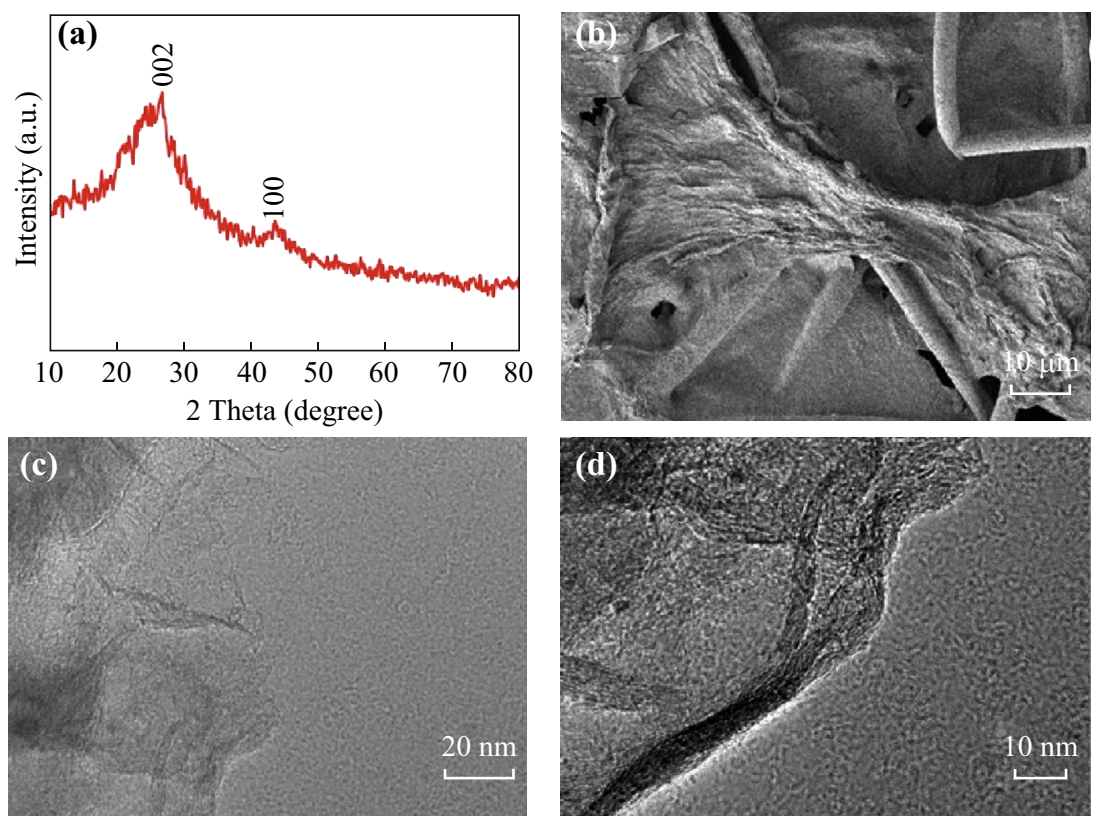

Fig. 4 a XRD pattern of rGO@CC; b the SEM image of rGO@CC electrode; and (c, d) the TEM image of rGO

to the pseudocapacitance [37]. In addition, the long-term cycling stability of the CoAl-LDH electrode was evaluated by galvanostatic charge-discharge measurement for 2000 cycles at a current density of $10 \mathrm{~A} \mathrm{~g}^{-1}$. As shown in Fig. 3d, the specific capacitance of the CoAl-LDH electrode still remained $95.8 \%$ after 2000 cycles and suggested an excellent stability.

\subsection{Negative Electrode}

The XRD pattern of rGO is shown in Fig. 4a. It can clearly be observed that two diffraction peaks were located at $26^{\circ}$ and $43^{\circ}$, associated with the (002) and (100) planes of carbon, respectively. Moreover, the morphologies and microstructures of rGO were investigated by SEM and 
(a)

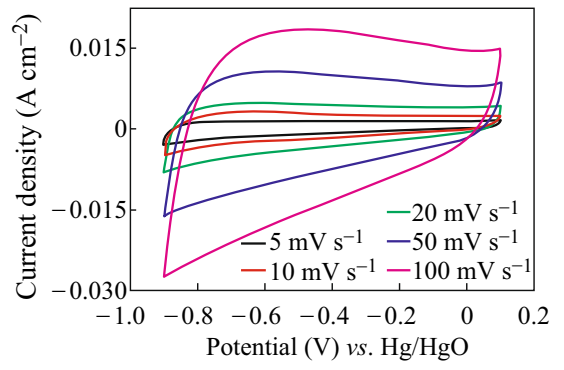

(c)

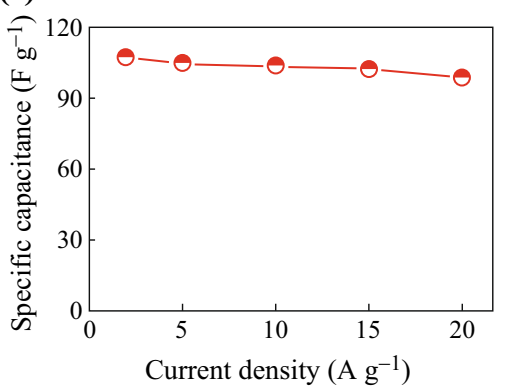

(b)

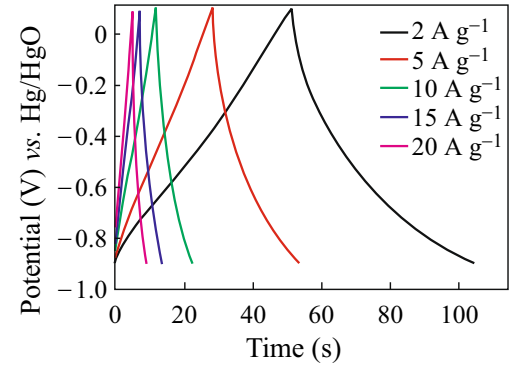

(d)

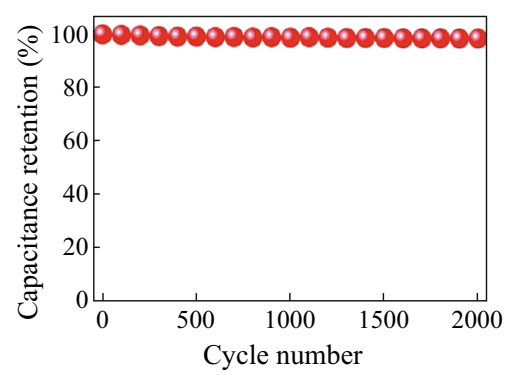

Fig. 5 Electrochemical performances of the rGO@CC electrode: a CVs at different scan rates; b GCD curves at different current densities; c Plot of specific capacitance versus current density; d Cycling performance during 2000 cycles at a large current density of $10 \mathrm{~A} \mathrm{~g}^{-1}$

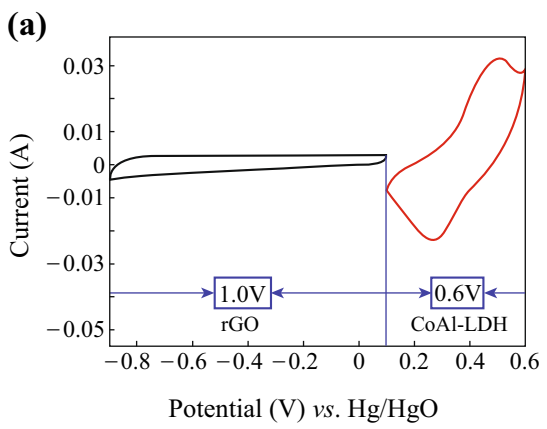

(c)

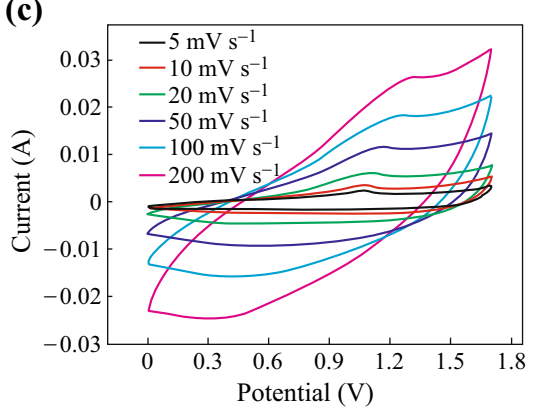

(b)

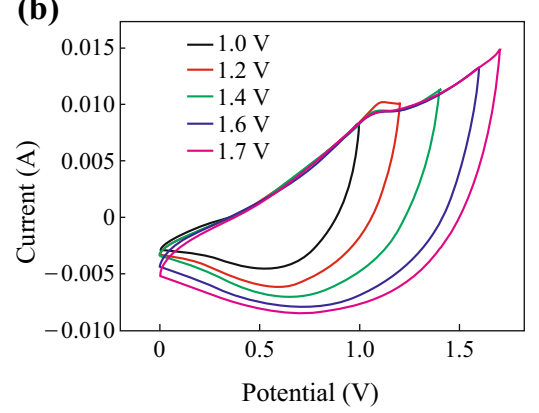

(d)

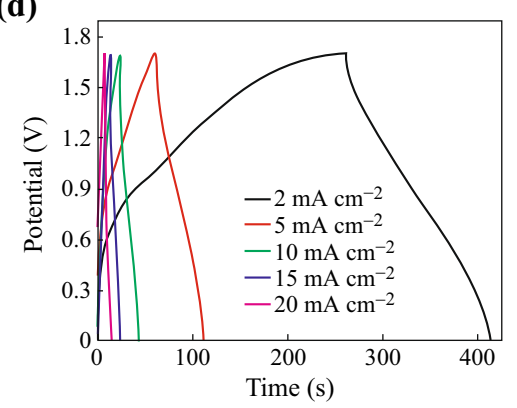

Fig. 6 a Comparison of the CV curves of positive and negative electrodes; b CV curves of the ASC at different voltages; $\mathbf{c}$ CV curves of ASC device at different scan rates; $\mathbf{d}$ GCD curves of ASC device at different current densities

TEM. Figure $4 \mathrm{~b}$ shows that $\mathrm{rGO}$ was coated well on the surface of the CC substrate to form 3D architectures, which could be beneficial in reducing aggregation of the rGO. The TEM in Fig. $4 c$, d revealed that rGO possessed a rippled silk veil structure with a wrinkled shape.
The electrochemical performance of $\mathrm{rGO}$ by $\mathrm{CV}$ and galvanostatic charge-discharge was measured in $6 \mathrm{M} \mathrm{KOH}$ aqueous solution over the potential range of 0.1 to $-0.9 \mathrm{~V}$. Figure 5a shows the $\mathrm{CV}$ curves of $\mathrm{rGO}$ at various scan rates from 5 to $100 \mathrm{mV} \mathrm{s}^{-1}$. The quasi-rectangular shape 
(a)

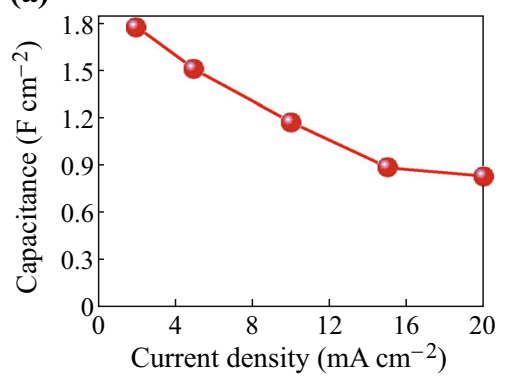

(c)

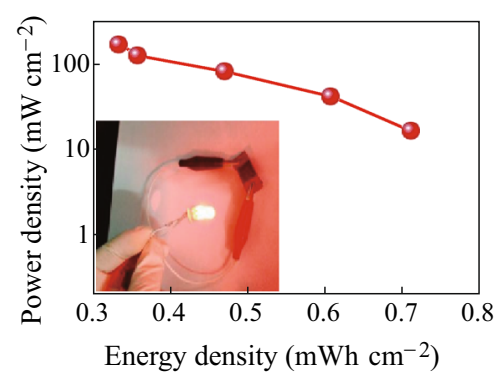

(b)

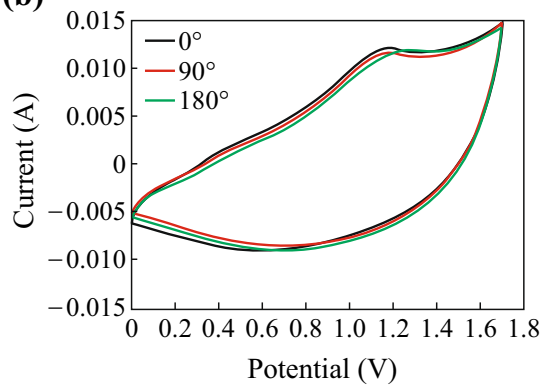

(d)

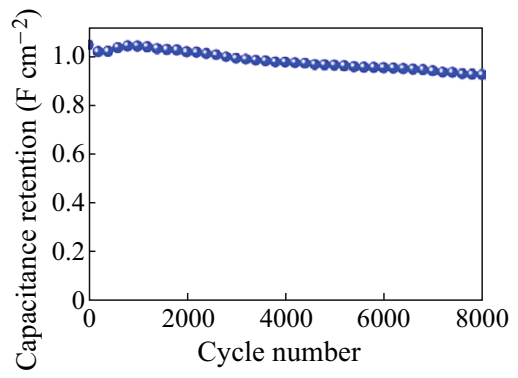

Fig. 7 a The capacitance calculated from Fig. 6d; b CV curves (at $50 \mathrm{mV} \mathrm{s}^{-1}$ ) under different bending conditions; $\mathbf{c}$ Ragone plot of ASC device (inset: a red LED lighted by ASC device); d Cycle stability of the ASC device at a current density of $15 \mathrm{~mA} \mathrm{~cm}{ }^{-2}$

Table 1 The comparison of the capacitive performance of CoAl-LDHs//rGO ASC with others

\begin{tabular}{|c|c|c|c|c|c|}
\hline ASC & $\begin{array}{l}\text { Areal capacitance } \\
\left(\mathrm{F} \mathrm{cm}^{-2}\right)\end{array}$ & Voltage (V) & $\begin{array}{l}\text { Energy density } \\
\left.(\mathrm{mWh} \mathrm{cm})^{-2}\right)\end{array}$ & $\begin{array}{l}\text { Power density } \\
\left(\mathrm{mW} \mathrm{cm}{ }^{-2}\right)\end{array}$ & References \\
\hline RGO@ $\mathrm{MnO}_{2} / / \mathrm{RGO}$ & 0.34 & 1.5 & 0.0115 & 3.80 & [38] \\
\hline $\mathrm{MnO}_{2} @$ PEDOT:PSS//AC & 1.67 & 2.0 & - & - & [39] \\
\hline $\mathrm{NiO} / / \mathrm{rGO}$ & 0.28 & 1.7 & - & - & {$[40]$} \\
\hline $\mathrm{PPy} @ \mathrm{MnO}_{2} / / \mathrm{AC}$ & 1.41 & 1.8 & 0.63 & 0.90 & [41] \\
\hline $\mathrm{NiCoO}_{4} @ \mathrm{Ni}_{3} \mathrm{~S}_{2} / / \mathrm{AC}$ & 2.25 & 1.8 & - & - & [42] \\
\hline CoAl-LDHs//rGO & 1.77 & 1.7 & 0.71 & 17.05 & This work \\
\hline
\end{tabular}

indicated its excellent electric double-layer capacitance. In particular, the shape of the $\mathrm{CV}$ curves did not change under a fast or slow scanning rate, indicating excellent stability. Figure $5 \mathrm{~b}$ shows the galvanostatic charge-discharge curves of rGO at different current densities $\left(2-20 \mathrm{~A} \mathrm{~g}^{-1}\right)$. All the charge-discharge curves possessed a symmetrical and linear triangle profile, implying that the rGO electrode had a rapid I-V response and charge-discharge reversibility. The specific capacitance of the rGO electrode at different charge-discharge current densities was calculated, as shown in Fig. 5c. We determined that the specific capacitance was about $110 \mathrm{~F} \mathrm{~g}^{-1}$ at a current density of $2 \mathrm{~A} \mathrm{~g}^{-1}$, along with $98 \mathrm{~F} \mathrm{~g}^{-1}$ at a current density of $20 \mathrm{~A} \mathrm{~g}^{-1}$. In addition, the stability of the capacitance of $\mathrm{rGO}$ was determined after 2000 cycles at a current density of $15 \mathrm{~A} \mathrm{~g}^{-1}$. As shown in Fig. 5d, the rGO electrode retained
98.5\% of its initial specific capacitance after 2000 cycles and exhibited outstanding cycling stability.

\subsection{Performance of ASC Based on CoAl-LDH and rGO Electrodes}

A flexible ASC was fabricated by using CC@CoAl-LDH as the positive electrode, CC@ $\mathrm{rGO}$ as the negative electrode, and $\mathrm{KOH} / \mathrm{PVA}$ as the gelled electrolyte. To achieve the best electrochemical performance of ASC, the charge balance should be $q^{+}=q^{-} \cdot q=C \times \Delta E \times m$, where $C$ represents the specific capacitance of the electrode material, $\Delta E$ is the voltage window of the charge-discharge process, and $\mathrm{m}$ is the mass of active materials. To obtain $q^{+}=q^{-}$, the mass of active materials on the electrode must be: 
$\frac{m_{+}}{m_{-}}=\frac{C_{-} \times \Delta E_{-}}{C_{+} \times \Delta E_{+}}$

Hence, based on the value of the specific capacitance and voltage window for the CoAl-LDH and rGO electrodes, the optimal mass ratio between two electrodes was about 1:6.

Figure 6a shows a comparison of the $\mathrm{CV}$ curves of the positive (CoAl-LDHs) and negative (rGO) electrodes. It could be seen that the potential difference between the two electrodes was $1.6 \mathrm{~V}$, and hence, the fabricated ASC could operate over a voltage window of $1.6 \mathrm{~V}$. To verify this, the fabricated ASC was subjected to $\mathrm{CV}$ tests at different voltages from 1 to $1.7 \mathrm{~V}$. As shown in Fig. 6b, the fabricated ASC revealed a stable capacitive behavior even when the voltage window reached up to $1.7 \mathrm{~V}$. The enhanced performance could be ascribed to the synergistic effect between the CoAl-LDH and rGO electrodes. To further assess the performance of the ASC, CV and galvanostatic charge-discharge were performed. As shown in Fig. 6c, the flexible ASC exhibited rectangular CV curves, and the current clearly increased as the scan rate increases, implying excellent rate capability. All the GCD curves obtained with different current densities $\left(2-20 \mathrm{~mA} \mathrm{~cm}^{-1}\right)$ over a potential window of $1.7 \mathrm{~V}$ (Fig. 6d) showed typical triangular shapes, representing a well-balanced charge storage. The areal specific capacitance (Fig. 7a) of ASC calculated from the galvanostatic charge-discharge curves under different current densities was $1.77,1.51,1.17,0.89$, and $0.83 \mathrm{~F} \mathrm{~cm}^{-2}$ at $2,5,10,15$, and $20 \mathrm{~mA} \mathrm{~cm}^{-2}$.

The mechanical flexibility of the ASC is very important for wearable applications. Interestingly, no apparent changes in the $\mathrm{CV}$ curves were observed under different bending conditions (Fig. 7b). That is, the capacitance remained almost unchanged as the bending angles changed from $0^{\circ}$ to $180^{\circ}$. These results proved the excellent mechanical flexibility of the ASC. Furthermore, the energy density and power density of the ASC are shown in a Ragone plot (Fig. 7c), which are calculated using the following equations:

$E=0.5 \times C_{\mathrm{m}} \times(\Delta V)^{2}$

$P_{\mathrm{av}}=\frac{E}{\Delta t}$

where $C_{\mathrm{m}}\left(\mathrm{F} \mathrm{cm}^{-2}\right)$ represents the specific capacitance of ASC, $\Delta V(\mathrm{~V})$ is the operating voltage of the cell, $\Delta t(\mathrm{~s})$ is the discharge time, $E\left(\mathrm{Wh} \mathrm{cm}^{-2}\right)$ is the energy density, and $P_{\text {av }}\left(\mathrm{W} \mathrm{cm}^{-2}\right)$ is the power density. The as-fabricated FASC devices showed a high energy density of $0.71 \mathrm{mWh} \mathrm{cm}^{-2}$ at a power density of $17.05 \mathrm{~mW} \mathrm{~cm}^{-2}$. As listed in Table 1, the CoAl-LDHs//rGO presented a high capacitance, energy density, and power density compared to others. In addition, the charged flexible ASC was able to power a commercial light-emitting diode (LED), as shown in the inset of Fig. 7c, implying the use of ASC for practical applications. The long-term cycling stability of the ASC device (Fig. 7d) was measured under galvanostatic charge-discharge at the current density of $15 \mathrm{~mA} \mathrm{~cm}^{-2}$. After 8000 cycles, the capacitance was reversibly maintained with only $7.1 \%$ loss of the initial value.

\section{Conclusion}

A flexible asymmetric supercapacitor has been successfully fabricated by using CC@CoAl-LDHs as the positive electrode and CC@rGO as the negative electrode. PVA/ $\mathrm{KOH}$ gel was used both as the electrolyte and the separator. Superior electrochemical properties of the flexible ASC were obtained, including high superficial specific capacitance of $1.77 \mathrm{~F} \mathrm{~cm}^{-2}$ at a current density of $2 \mathrm{~mA} \mathrm{~cm}^{-2}$, a wide operating potential of $1.7 \mathrm{~V}$, and a high energy density of $0.71 \mathrm{mWh} \mathrm{cm}^{-2}$ at a power density of $17.05 \mathrm{~mW} \mathrm{~cm}^{-2}$. Importantly, this flexible ASC will find wide applications in portable electronic devices and hybrid vehicles.

Acknowledgements This work was supported by National Natural Science Foundation of China (21376105 and 21576113) and Foshan Innovative and Entepreneurial Research Team Program (No. 2014IT100062).

Open Access This article is distributed under the terms of the Creative Commons Attribution 4.0 International License (http://crea tivecommons.org/licenses/by/4.0/), which permits unrestricted use, distribution, and reproduction in any medium, provided you give appropriate credit to the original author(s) and the source, provide a link to the Creative Commons license, and indicate if changes were made.

\section{References}

1. T. Li, G.H. Li, L.H. Li, L. Liu, Y. Xu, H.Y. Ding, T. Zhang, Large-scale self-assembly of 3D flower-like hierarchical Ni/CoLDHs microspheres for high-performance flexible asymmetric supercapacitors. ACS Appl. Mater. Interfaces 8, 2562-2572 (2016). doi:10.1021/acsami.5b10158

2. M. Shao, Z. Li, R. Zhang, F. Ning, M. Wei, D.G. Evans, X. Duan, Hierarchical conducting polymer@clay core-shell arrays for flexible all-solid-state supercapacitor devices. Small 11, 3530-3538 (2015). doi:10.1002/smll.201403421

3. Y. Li, J. Dong, J. Zhang, X. Zhao, P. Yu, L. Jin, Q. Zhang, Nitrogen-doped carbon membrane derived from polyimide as free-standing electrodes for flexible supercapacitors. Small 11, 3476-3484 (2015). doi:10.1002/smll.201403575

4. Z. Qi, A. Younis, D. Chu, S. Li, A facile and template-free onepot synthesis of $\mathrm{Mn}_{3} \mathrm{O}_{4}$ nanostructures as electrochemical supercapacitors. Nano-Micro Lett. 8, 165-173 (2015). doi:10. 1007/s40820-015-0074-0

5. Z.H. Wang, D.O. Carlsson, P. Tammela, K. Hua, P. Zhang, L. Nyholm, M. Stromme, Surface modified nanocellulose fibers 
yield conducting polymer-based flexible supercapacitors with enhanced capacitances. ACS Nano 9, 7563-7571 (2015). doi:10. 1021/acsnano.5b02846

6. Z. Li, M. Shao, L. Zhou, R. Zhang, C. Zhang, J. Han, M. Wei, D.G. Evans, X. Duan, A flexible all-solid-state micro-supercapacitor based on hierarchical $\mathrm{CuO} @$ layered double hydroxide core-shell nanoarrays. Nano Energy 20, 294-304 (2016). doi:10. 1016/j.nanoen.2015.12.030

7. H. Chen, S. Zeng, M. Chen, Y. Zhang, Q. Li, Fabrication and functionalization of carbon nanotube films for high-performance flexible supercapacitors. Carbon 92, 271-296 (2015). doi:10. 1016/j.carbon.2015.04.010

8. G.S. Gund, D.P. Dubal, N.R. Chodankar, J.Y. Cho, P. GomezRomero, C. Park, C.D. Lokhande, Low-cost flexible supercapacitors with high-energy density based on nanostructured $\mathrm{MnO}_{2}$ and $\mathrm{Fe}_{2} \mathrm{O}_{3}$ thin films directly fabricated onto stainless steel. Sci. Rep. 5, 12454 (2015). doi:10.1038/srep12454

9. X. Zang, X. Li, M. Zhu, X. Li, Z. Zhen, Y. He, K. Wang, J. Wei, F. Kang, H. Zhu, Graphene/polyaniline woven fabric composite films as flexible supercapacitor electrodes. Nanoscale 7, 7318-7322 (2015). doi:10.1039/c5nr00584a

10. T.M. Masikhwa, M.J. Madito, D.Y. Momodu, J.K. Dangbegnon, O. Guellati et al., High performance asymmetric supercapacitor based on CoAl-LDH/GF and activated carbon from expanded graphite. RSC Adv. 6, 46723-46732 (2016). doi:10.1039/ c6ra07419g

11. X. Dong, L. Wang, D. Wang, C. Li, J. Jin, Layer-by-layer engineered $\mathrm{Co}-\mathrm{Al}$ hydroxide nanosheets/graphene multilayer films as flexible electrode for supercapacitor. Langmuir $\mathbf{2 8}$, 293-298 (2012). doi:10.1021/la2038685

12. J. Zhao, J. Chen, S. Xu, M. Shao, Q. Zhang, F. Wei, J. Ma, M. Wei, D.G. Evans, X. Duan, Hierarchical NiMn layered double hydroxide/carbon nanotubes architecture with superb energy density for flexible supercapacitors. Adv. Funct. Mater. 24, 2938-2946 (2014). doi:10.1002/adfm.201303638

13. L.F. Chen, Z.Y. Yu, X. Ma, Z.Y. Li, S.H. Yu, In situ hydrothermal growth of ferric oxides on carbon cloth for low-cost and scalable high-energy-density supercapacitors. Nano Energy 9, 345-354 (2014). doi:10.1016/j.nanoen.2014.07.021

14. L. Wang, D. Wang, X.Y. Dong, Z.J. Zhang, X.F. Pei, X.J. Chen, B. Chen, J. Jin, Layered assembly of graphene oxide and Co-Al layered double hydroxide nanosheets as electrode materials for supercapacitors. Chem. Commun. 47, 3556-3558 (2011). doi:10. 1039/c0cc05420h

15. X. Cao, B. Zheng, W. Shi, J. Yang, Z. Fan, Z. Luo, X. Rui, B. Chen, Q. Yan, H. Zhang, Reduced graphene oxide-wrapped $\mathrm{MoO}_{3}$ composites prepared by using metal-organic frameworks as precursor for all-solid-state flexible supercapacitors. Adv. Mater. 27, 4695-4701 (2015). doi:10.1002/adma.201501310

16. J. Xu, Q.F. Wang, X.W. Wang, Q.Y. Xiang, B. Hang, D. Chen, G.Z. Shen, Flexible asymmetric supercapacitors based upon $\mathrm{Co}_{9} \mathrm{~S}_{8}$ nanorod $/ / \mathrm{Co}_{3} \mathrm{O}_{4} @ \mathrm{RuO}_{2}$ nanosheet arrays on carbon cloth. ACS Nano 7, 5453-5462 (2013). doi:10.1021/nn401450s

17. W. Lin, W. Yu, Z. Hu, W. Ouyang, X. Shao, R. Li, D.S. Yuan, Superior performance asymmetric supercapacitors based on flake-like $\mathrm{Co} / \mathrm{Al}$ hydrotalcite and graphene. Electrochim. Acta 143, 331-339 (2014). doi:10.1016/j.electacta.2014.08.024

18. P. Sun, Z. Deng, P. Yang, X. Yu, Y. Chen, Z. Liang, H. Meng, W. Xie, S. Tan, W. Mai, Freestanding $\mathrm{CNT}-\mathrm{WO}_{3}$ hybrid electrodes for flexible asymmetric supercapacitors. J. Mater. Chem. A 3, 12076-12080 (2015). doi:10.1039/c5ta02316e

19. M. Boota, B. Anasori, C. Voigt, M.Q. Zhao, M.W. Barsoum, Y. Gogotsi, Pseudocapacitive electrodes produced by oxidant-free polymerization of pyrrole between the layers of $2 \mathrm{D}$ titanium carbide (MXene). Adv. Mater. 28, 1517-1522 (2016). doi:10. 1002/adma.201504705
20. G. Sun, X. Zhang, R. Lin, J. Yang, H. Zhang, P. Chen, Hybrid fibers made of molybdenum disulfide, reduced graphene oxide, and multi-walled carbon nanotubes for solid-state, flexible, asymmetric supercapacitors. Angew. Chem. Int. Ed. 54, 4651-4656 (2015). doi:10.1002/anie.201411533

21. X. Wu, L. Jiang, C. Long, T. Wei, Z. Fan, Dual support system ensuring porous co-al hydroxide nanosheets with ultrahigh rate performance and high energy density for supercapacitors. Adv. Funct. Mater. 25, 1648-1655 (2015). doi:10.1002/adfm. 201404142

22. W. Yu, W. Lin, X. Shao, Z. Hu, R. Li, D. Yuan, High performance supercapacitor based on $\mathrm{Ni}_{3} \mathrm{~S}_{2}$ /carbon nanofibers and carbon nanofibers electrodes derived from bacterial cellulose. J. Power Sources 272, 137-143 (2014). doi:10.1016/j.jpowsour. 2014.08.064

23. J. Chen, X. Wang, J. Wang, P.S. Lee, Sulfidation of NiMn-layered double hydroxides/graphene oxide composites toward supercapacitor electrodes with enhanced performance. Adv. Energy Mater. 6, 1501745 (2016). doi:10.1002/aenm.201501745

24. J. Tao, W. Ma, N. Liu, X. Ren, Y. Shi, J. Su, Y. Gao, Highperformance solid-state supercapacitors fabricated by pencil drawing and polypyrrole depositing on paper substrate. NanoMicro Lett. 7, 276-281 (2015). doi:10.1007/s40820-015-0039-3

25. M. Li, F. Liu, J.P. Cheng, J. Ying, X.B. Zhang, Enhanced performance of nickel-aluminum layered double hydroxide nanosheets/carbon nanotubes composite for supercapacitor and asymmetric capacitor. J. Alloys Compd. 635, 225-232 (2015). doi:10.1016/j.jallcom.2015.02.130

26. L. Li, Q. Zhong, N.D. Kim, G. Ruan, Y. Yang et al., Nitrogendoped carbonized cotton for highly flexible supercapacitors. Carbon 105, 260-267 (2016). doi:10.1016/j.carbon.2016.04.031

27. M.A. Bissett, I.A. Kinloch, R.A. Dryfe, Characterization of $\mathrm{MoS}_{2}$-graphene composites for high-performance coin cell supercapacitors. ACS Appl. Mater. Interfaces 7, 17388-17398 (2015). doi:10.1021/acsami.5b04672

28. Y.P. Chen, B.R. Liu, Q. Liu, J. Wang, Z.S. Li, X.Y. Jing, L.H. $\mathrm{Liu}$, Coaxial $\mathrm{CoMoO}_{4}$ nanowire arrays with chemically integrated conductive coating for high-performance flexible all-solidstate asymmetric supercapacitors. Nanoscale 7, 15159-15167 (2015). doi:10.1039/C5NR02961A

29. L. Jiang, L. Sheng, C. Long, T. Wei, Z. Fan, Functional pillared graphene frameworks for ultrahigh volumetric performance supercapacitors. Adv. Energy Mater. 5, 1500771 (2015). doi:10. 1002/aenm.201500771

30. M. Li, J.P. Cheng, F. Liu, X.B. Zhang, 3D-architectured nickelcobalt-manganese layered double hydroxide/reduced graphene oxide composite for high-performance supercapacitor. Chem. Phys. Lett. 640, 5-10 (2015). doi:10.1016/j.cplett.2015.10.003

31. A.D. Jagadale, G. Guan, X. Li, X. Du, X. Ma, X. Hao, A. Abudula, Ultrathin nanoflakes of cobalt-manganese layered double hydroxide with high reversibility for asymmetric supercapacitor. J. Power Sources 306, 526-534 (2016). doi:10.1016/j.jpowsour. 2015.12.097

32. Z. Huang, S. Wang, J. Wang, Y. Yu, J. Wen, R. Li, Exfoliationrestacking synthesis of coal-layered double hydroxide nanosheets/reduced graphene oxide composite for high performance supercapacitors. Electrochim. Acta 152, 117-125 (2015). doi:10. 1016/j.electacta.2014.11.085

33. Z.Y. Yu, L.F. Chen, S.H. Yu, Growth of $\mathrm{NiFe}_{2} \mathrm{O}_{4}$ nanoparticles on carbon cloth for high performance flexible supercapacitors. J. Mater. Chem. A 2, 10889 (2014). doi:10.1039/c4ta00492b

34. J. Wen, S. Li, K. Zhou, Z. Song, B. Li, Z. Chen, T. Chen, Y. Guo, G. Fang, Flexible coaxial-type fiber solid-state asymmetrical supercapacitor based on $\mathrm{Ni}_{3} \mathrm{~S}_{2}$ nanorod array and pen ink electrodes. J. Power Sources 324, 325-333 (2016). doi:10.1016/j. jpowsour.2016.05.087 
35. X. Yang, K. Xu, R. Zou, J. Hu, A hybrid electrode of $\mathrm{Co}_{3-}$ $\mathrm{O}_{4} @ \mathrm{PPy}$ core/shell nanosheet arrays for high-performance supercapacitors. Nano-Micro Lett. 8, 143-150 (2015). doi:10. 1007/s40820-015-0069-x

36. S. Huang, G.N. Zhu, C. Zhang, W.W. Tjiu, Y.Y. Xia, T. Liu, Immobilization of Co-Al layered double hydroxides on graphene oxide nanosheets: growth mechanism and supercapacitor studies. ACS Appl. Mater. Interfaces 4, 2242-2249 (2012). doi:10.1021/ am300247x

37. J.X. Feng, S.H. Ye, X.F. Lu, Y.X. Tong, G.R. Li, Asymmetric paper supercapacitor based on amorphous porous $\mathrm{Mn}_{3} \mathrm{O}_{4}$ negative electrode and $\mathrm{Ni}(\mathrm{OH})_{2}$ positive electrode: a novel and highperformance flexible electrochemical energy storage device. ACS Appl. Mater. Interfaces 7, 11444-11451 (2015). doi:10.1021/ acsami.5b02157

38. B. Liu, D. Kong, Z.X. Huang, R. Mo, Y. Wang, Z. Han, C. Cheng, H.Y. Yang, Three-dimensional hierarchical $\mathrm{NiCo}_{2} \mathrm{O}_{4}$ nanowire@ $\mathrm{Ni}_{3} \mathrm{~S}_{2}$ nanosheet core/shell arrays for flexible asymmetric supercapacitors. Nanoscale 8, 10686-10694 (2016). doi:10.1039/C6NR02600A
39. Z. Su, C. Yang, C. Xu, H. Wu, Z. Zhang, T. Liu, C. Zhang, Q. Yang, B. Li, F. Kang, Co-electro-deposition of the $\mathrm{MnO}_{2}-\mathrm{PED}-$ OT:PSS nanostructured composite for high areal mass, flexible asymmetric supercapacitor devices. J. Mater. Chem. A 1, 12432 (2013). doi:10.1039/C3TA13148C

40. A. Sumboja, C.Y. Foo, X. Wang, P.S. Lee, Large areal mass, flexible and free-standing reduced graphene oxide/manganese dioxide paper for asymmetric supercapacitor device. Adv. Mater. 25, 2809-2815 (2013). doi:10.1002/adma.201205064

41. J. Tao, N. Liu, L. Li, J. Su, Y. Gao, Hierarchical nanostructures of polypyrrole@ $\mathrm{MnO}_{2}$ composite electrodes for high performance solid-state asymmetric supercapacitors. Nanoscale 6, 2922-2928 (2014). doi:10.1039/C3NR05845J

42. W. Zilong, Z. Zhu, J. Qiu, S. Yang, High performance flexible solid-state asymmetric supercapacitors from $\mathrm{MnO}_{2} / \mathrm{ZnO}$ coreshell nanorods//specially reduced graphene oxide. J. Mater. Chem. C 2, 1331-1336 (2014). doi:10.1039/C3TC31476F 